\title{
Dr.Pradeep Fernando \\ Consultant Orthopaedic Surgeon and Emeritus Editor of the Sri Lanka Journal of Surgery
}

The news of the untimely demise of Dr.Pradeep Fernando was truly saddening to many of us who were near and dear to him.

Born as the only child to Mr. Clement Fernando and Dr(Mrs.)Selvajothy Fernando from Galle Pradeep's early life was spent in Galle and Kurunegala. After successfully completing his studies up to the GCE ordinary level at St. Peter's College, Pradeep moved to Royal College, Colombo for his Advanced Level studies. He excelled in academic work as well as in sports at both schools. Pradeep's enthusiasm and active participation in extracurricular activities at school would have moulded his character very much. At Royal he was the President of the English Literary Society and also the captain of the debating team and won the prestigious J.R. Jayawardane Award for the best

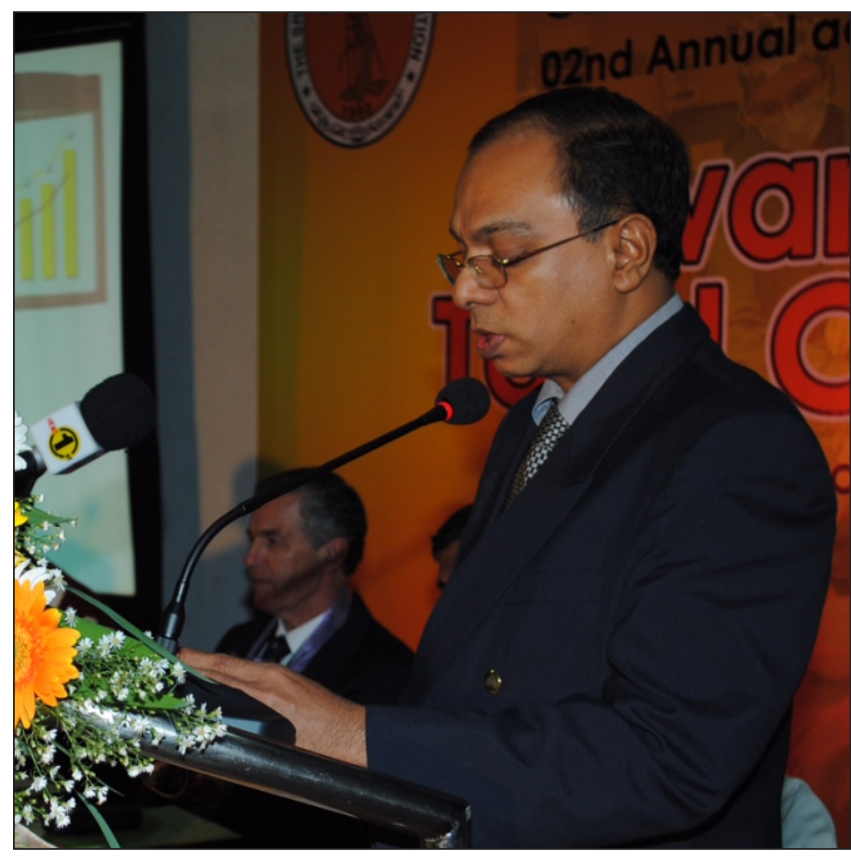
speaker. Pradeep enjoyed music and reading. His creativity and talents were much displayed when he produced a drama at the college. He performed exceptionally well in Advanced Level Examination securing a place at the Colombo Medical Faculty winning the Prize for Zoology from the college. He excelled in studies at the Faculty and passed the Final MBBS Examination with Second Class Honors.

My association with Pradeep goes back to the time when he was a medical student at the Colombo Medical Faculty. However I came to know him more closely, when he became my Senior Registrar after passing his Masters of Surgery Examination and opted to specialize in Orthopedic Surgery. He worked in my unit for 2 years as a Senior Registrar with dedication and hard work which contributed immensely to the smooth and efficient functioning of the unit. He served his patients with much care, conducted his duties with extreme diligence and willingly shared the responsibilities. Our association grew stronger when Pradeep was appointed as the Consultant Orthopedic Surgeon at Teaching Hospital, Ragama. He is one of the very few Orthopedic Surgeons who never hesitated to take a second opinion and regularly consulted a senior colleague whenever there was a difficult problem.

Pradeep was instrumental in reactivation of the Sri Lanka Orthopedic Association in year 2000 and held the post of Secretary from 2000-2004, making our association one of the most efficient associations in Sri Lanka. He organized the first AO course in Sri Lanka in the year 2000 at the Teaching Hospital, Ragama. Since then he organized several AO courses in Sri Lanka in Association with AO International. He was the AO coordinator in Sri Lanka and participated in $\mathrm{AO}$ activities in the Regional Countries too.

He was a regular attendee of the outreach programms of the Sri Lanka Orthopedic Association conducted in remote places in the country. He was a Council member of Sri Lanka Orthopedic Association and was the Vice President at the time his death. 
Pradeep took a keen interest in developing health care in Sri Lanka; surgery in general and orthopedic surgery in particularly. He was a member of Board of Study in Surgery and Specialty Board in Orthopedic Surgery. He was also an examiner for MD part 1 Surgery and MD Orthopedic Surgery Final Examination. At one time he was the Assistant Secretary of the College of Surgeons of Sri Lanka and was the editor of the College Journal. During his tenure he was able to publish the journal regularly and bring it up to international standards. Through these positions he contributed much to the college and to the welfare of the members of the College of the Surgeons of Sri Lanka.

He was a live wire to the World Bank funded Health Sector Development Project. He single handedly handled most important parts of the project and travelled all over the country to get the maximum benefit of the project to the country. His efforts in the project brought enormous profits in developing much needed human resources in the health sector and also brought in much needed finances to the College.

Pradeep was happily married to Janaki, Professor of Pathology, University of Kelaniya whom he met at the Faculty of Medicine, Colombo while he was a student. They were blessed with a son Sahishna who is studying Business Management in the United Kingdom.

He was a person dedicated to his profession. When there was a disturbance in Pakistan and required medical help he was one of the first to travel to that country offering his services. With his demise Sri Lanka lost a dynamic, enthusiastic and hard working young surgeon whose contribution to society, to the Surgical and Orthopedic community was enormous. The void created by his demise will take a long time to fill.

May he attain the supreme bliss of Nibbana.

Dr. Upali Banagala 